\title{
Prospective Multicentre Study on the Epidemiology and Current Therapeutic Management of Severe Bronchiolitis in Spain
}

\author{
Jose C. Flores-González, ${ }^{1}$ Juan Mayordomo-Colunga, ${ }^{2}$ \\ Iolanda Jordan, ${ }^{3}$ Alicia Miras-Veiga, ${ }^{4}$ Cristina Montero-Valladares, ${ }^{5}$ \\ Marta Olmedilla-Jodar, ${ }^{6}$ Andrés J. Alcaraz-Romero, ${ }^{7}$ Miren Eizmendi-Bereciartua, \\ Francisco Fernández-Carrión, ${ }^{9}$ Carmen Santiago-Gutierrez, ${ }^{10}$ Esther Aleo-Luján, ${ }^{11}$ \\ Sonia Pérez-Quesada, ${ }^{12}$ Cristina Yun-Castilla, ${ }^{13}$ Carmen Martín, ${ }^{14}$ \\ Álvaro Navarro-Mingorance, ${ }^{15}$ and Concha Goñi-Orayen ${ }^{16}$ \\ ${ }^{1}$ Unidad de Cuidados Intensivos Pediátricos, Hospital Universitario Puerta del Mar, Cádiz, Spain \\ ${ }^{2}$ Sección de Cuidados Intensivos Pediátricos, Hospital Universitario Central de Asturias, Oviedo, Spain \\ ${ }^{3}$ Unidad de Cuidados Intensivos Pediátricos, Hospital Sant Joan de Déu Barcelona, Barcelona, Spain \\ ${ }^{4}$ Unidad de Cuidados Intensivos Pediátricos, Hospital de Burgos, Burgos, Spain \\ ${ }^{5}$ Unidad de Cuidados Intensivos Pediátricos, Hospital Universitario Virgen Del Rocío, Sevilla, Spain \\ ${ }^{6}$ Unidad de Cuidados Intensivos Pediátricos, Hospital 12 de Octubre, Madrid, Spain \\ ${ }^{7}$ Unidad de Cuidados Intensivos Pediátricos, Hospital Universitario Gregorio Marañón, Madrid, Spain \\ ${ }^{8}$ Unidad de Cuidados Intensivos Pediátricos, Hospital Universitario Donostia, San Sebastián, Spain \\ ${ }^{9}$ Unidad de Cuidados Intensivos Pediátricos, Hospital Universitario de Salamanca, Salamanca, Spain \\ ${ }^{10}$ Unidad de Cuidados Intensivos Pediátricos, Hospital de Jaén, Jaén, Spain \\ ${ }^{11}$ Unidad de Cuidados Intensivos Pediátricos, Hospital Clínico San Carlos, Madrid, Spain \\ ${ }^{12}$ Unidad de Cuidados Intensivos Pediátricos, Hospital General Universitario de Alicante, Alicante, Spain \\ ${ }^{13}$ Unidad de Cuidados Intensivos Pediátricos, Hospital Universitario Regional de Málaga, Málaga, Spain \\ ${ }^{14}$ Unidad de Cuidados Intensivos Pediátricos, Hospital Virgen de la Salud, Toledo, Spain \\ ${ }^{15}$ Unidad de Cuidados Intensivos Pediátricos, Hospital Virgen de la Arrixaca, Murcia, Spain \\ ${ }^{16}$ Unidad de Cuidados Intensivos Pediátricos, Complejo Hospitalario de Pamplona, Pamplona, Spain
}

Correspondence should be addressed to Jose C. Flores-González; carlosflogon@gmail.com

Received 26 November 2016; Revised 14 February 2017; Accepted 27 February 2017; Published 22 March 2017

Academic Editor: Paolo Spagnolo

Copyright (C) 2017 Jose C. Flores-González et al. This is an open access article distributed under the Creative Commons Attribution License, which permits unrestricted use, distribution, and reproduction in any medium, provided the original work is properly cited.

Objective. To determine the epidemiology and therapeutic management of patients with severe acute bronchiolitis (AB) admitted to paediatric intensive care units (PICUs) in Spain. Design. Descriptive, prospective, multicentre study. Setting. Sixteen Spanish PICUs. Patients. Patients with severe AB who required admission to any of the participating PICUs over 1 year. Interventions. Both epidemiological variables and medical treatment received were recorded. Results. A total of 262 patients were recruited; 143 were male $(54.6 \%)$, with median age of 1 month (0-23). Median stay in the PICU was 7 days (1-46). Sixty patients (23\%) received no nebuliser treatment, while the rest received a combination of inhalation therapies. One-quarter of patients (24.8\%) received corticosteroids and 56.5\% antibiotic therapy. High-flow oxygen therapy was used in $14.3 \%$ and noninvasive ventilation (NIV) was used in $75.6 \%$. Endotracheal intubation was required in $24.4 \%$ of patients. Younger age, antibiotic therapy, and invasive mechanical ventilation (IMV) were risk factors that significantly increased the stay in the PICU. Conclusions. Spanish PICUs continue to routinely use nebulised bronchodilator treatment and corticosteroid therapy. Despite NIV being widely used in this condition, intubation was required in one-quarter of cases. Younger age, antibiotic therapy, and IMV were associated with a longer stay in the PICU. 


\section{Introduction}

Bronchiolitis is the most frequent cause of lower respiratory tract infection in infants and the predominant reason for admission in children under 1 year of age $[1,2]$. Respiratory syncytial virus (RSV) is the most common aetiological agent and the one that determines the seasonal nature of the condition [3]. Around $2 \%-5 \%$ of patients with acute bronchiolitis $(\mathrm{AB})$ require hospital admission; of these, $3 \%-11 \%$ will require admission to a paediatric intensive care unit (PICU) [4]. However, when the group of patients with risk factors for severe bronchiolitis is analysed, this figure reaches $9.4 \%-50 \%$. Although a series of risk factors for severity have been identified, most patients admitted to the PICU do not present any of these $[1,5]$.

Despite the significant care demands and high number of hospital admissions, few therapeutic alternatives have been shown to be effective [6]. Numerous studies have shown wide variation in the therapeutic management of moderate $A B$ $[7,8]$. Despite a lack of evidence, personal or institutional preferences are often maintained when $\mathrm{AB}$ patients require admission to the PICU $[7,8]$.

High-flow oxygen therapy and noninvasive ventilation (NIV) are increasingly used to the detriment of invasive mechanical ventilation (IMV) $[9,10]$. Although studies assessing the use of high-flow therapy in bronchiolitis suggest that it can reduce the work of breathing (WOB) and endotracheal intubation rate, this is not recommended in the latest systematic review [11]. Similarly, the latest systematic review on continuous positive airway pressure (CPAP) concluded that the scant evidence available to support the claim that it reduces the $\mathrm{WOB}$ in bronchiolitis is based on poorly designed studies and that no conclusions can be drawn on its effect [12]. There are various indications and modalities of invasive respiratory support in infants with severe $A B$, but to date no modality has been proven to be superior to any other, although this has not been corroborated in clinical trials.

With respect to the above, the aim of this study was to prospectively determine the epidemiology of patients with severe AB admitted to PICUs in Spain and to describe their therapeutic management.

\section{Materials and Methods}

This is a descriptive, prospective, multicentre study in which 16 Spanish PICUs from the following hospitals participated: Hospital Universitario Puerta del Mar (Cádiz), Hospital Universitario Central de Asturias (Oviedo), Hospital Sant Joan de Déu (Barcelona), Hospital de Burgos, Hospital Universitario Virgen Del Rocío (Sevilla), Hospital 12 de Octubre (Madrid), Hospital Universitario Gregorio Marañón (Madrid), Hospital Universitario Donostia (San Sebastián), Hospital Universitario de Salamanca, Hospital de Jaén, Hospital Clínico San Carlos (Madrid), Hospital Universitario Regional de Málaga, Hospital General Universitario de Alicante, Hospital Virgen de la Salud (Toledo), Complejo Hospitalario de Pamplona, and Hospital Virgen de la Arrixaca (Murcia).

Patients with severe $A B$ who required admission to any of the participating PICUs over 1 epidemiological year (from
1 October 2014 to 15 May 2015) were included; parents or guardians signed an informed consent. Inclusion criteria were (1) infant aged under 24 months with a clinical diagnosis of $\mathrm{AB}[1,13]$, (2) presenting with bronchiolitis classified as severe, and (3) informed consent form signed by the parents or guardians. Exclusion criteria were admission of a patient with $\mathrm{AB}$ for reasons of age or episodes of apnoea with no severity criterion, having presented previous episodes of respiratory distress, and refusal of parent or guardian to sign the informed consent form. Bronchiolitis was defined as the first episode of respiratory distress with wheezing and/or crackles associated with symptoms of upper respiratory tract infection during the epidemic period [1]. Criteria for admission to the PICU were defined as follows: severe respiratory failure with a score of $>7$ on the Wood-DownesFerrés scoring system [14] or $>10$ on the Sant Joan de Déu hospital scale [15] and respiratory acidosis: $\mathrm{pH}<7.2, \mathrm{SatO}_{2}<$ $90 \%$ with $\mathrm{FiO}_{2}$ 40\%, cyanosis with oxygen therapy, severe extrapulmonary symptoms, altered level of consciousness, or rapidly progressive disease.

The following variables were recorded during admission: demographic characteristics (medical record number, sex, date of birth, and town/city); stay in PICU with date of admission and discharge and hospital stay after PICU discharge; family history of atopy (atopic dermatitis, asthma, or allergic rhinitis) or smoking; personal history of atopy (atopic dermatitis); type of feeding received so far: breast-fed, bottle-fed, or mixed; presence of risk factors for severity (prematurity, heart disease, bronchopulmonary dysplasia, neuromuscular disease, or immunodeficiency); origin of admission (hospital ward, emergency department, or other hospitals); result of RSV test; reason for admission to PICU (deterioration in clinical condition, presence of risk factors, including age, presence of apnoea, and abnormal blood gas results); analytic result at PICU admission ( $\mathrm{pH}$ and venous $\mathrm{pCO}_{2}$ ); medical treatment received during the stay in the PICU (adrenaline, salbutamol, corticosteroids, and 3\% hypertonic saline solution [3\% HSS]); antibiotic therapy and reason for use (clinical deterioration, increased acute phase reactants, radiological image, or others); treatment or prophylaxis with palivizumab; respiratory support received during stay in the PICU (oxygen therapy, high-flow oxygen, NIV, or invasive ventilation); need for high frequency ventilation; need for sedoanalgesia and/or muscle relaxation; complication with hospital-acquired pneumonia or exitus.

The diagnosis of pneumonia was established according to clinical (fever), analytical (increase of acute phase reactants), and radiological (appearance of acute condensation) parameters. For the diagnosis of pneumonia associated with mechanical ventilation, the criteria of the CDC were used.

2.1. Statistical Analysis. Variables were collected in a database and analysed using the statistical package SPSS, version 21.

Descriptive results for the quantitative variables were expressed as measures of central tendency and dispersion. The mean and standard deviation were used in the case 


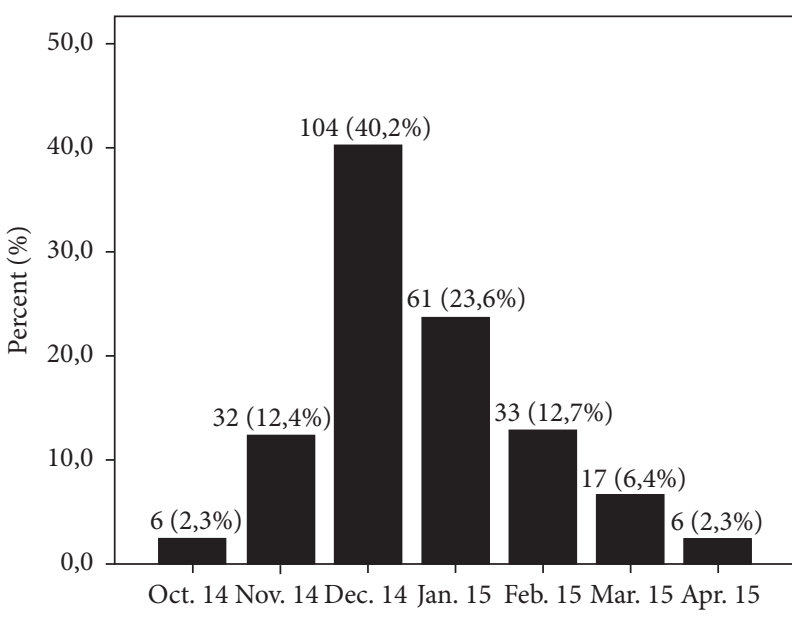

FIgURE 1: Percentage of admissions for bronchiolitis by month.

of variables that followed a normal distribution; otherwise, median and interquartile range were used. Qualitative variables were expressed as number and percentage. Normal distribution of the quantitative variables was assessed using the Kolmogorov-Smirnov test.

Student's $t$-test was used to compare 2 means in the case of parametric quantitative variables with homogeneous variances; if the variables were nonparametric and there was no homogeneity of variances, they were compared using Mann-Whitney $U$ test with Bonferroni correction.

For the multivariate analysis, linear regression models were fitted, first manually entering the variables previously found to be statistically significant in the bivariate analysis. Using this model with all the variables, variables that were not statistically significant were deleted one by one using the backward method, removing the nonsignificant variables from the model in each step.

2.2. Ethical Aspects. This study was approved by the local ethics committee. The parents or legal representatives of each patient were informed and asked for informed consent to collect the data described.

\section{Results}

A total of 262 patients were recruited in the 16 participating Spanish PICUs; $54.6 \%$ were male. Median age was 1 month (0-23). Median stay in the PICU was 7 days, and median hospital stay after admission at PICU was 4 days. Just over one-quarter of patients $(26.7 \%)$ presented some risk factor for severity, and 14 patients had received palivizumab (only two RSV+). Admission rates were highest in December and January (Figure 1).

The median number of days of respiratory distress until admission to the PICU was 2 days. The main criterion for admission to the PICU was severity (77.2\%). Epidemiological and clinical characteristics of the sample are described in Tables 1 and 2. Etiologically, only RSV was detected in the nasal mucus, the causative agent in $78 \%$ of the cases. The
TABLE 1: Epidemiological, family, and personal history characteristics of patients included in the BRUCIP study.

\begin{tabular}{ll}
\hline Variable & Value \\
\hline Sample size $(n)$ & 262 patients \\
Sex (male/female) & $143(54.6 \%) / 119(45.4 \%)$ \\
Age $^{*}$ & 1 month $(0-23$ days) \\
Weight $^{*}$ & 4.6 kg $(1.4-14)$ \\
Stay in PICU* & 7 days $(1-46)$ \\
Total hospital stay & 11 days (3-59 days) \\
FH of smoking & 83 patients $(31.7 \%)$ \\
FH of atopy & 66 patients $(25.2 \%)$ \\
Breast-feeding for at least first 15 days & 145 patients $(55.3 \%)$ \\
of life & 70 patients $(26.7 \%)$ \\
Risk factor for severity & (i) 55 patients $(21 \%)$ \\
$\quad$ (i) Premature & (ii) 10 patients $(3.81 \%)$ \\
$\quad$ (ii) Heart disease & (iii) 5 patients $(1.90 \%)$ \\
(iii) Respiratory disease & (iv) 2 patients $(0.8 \%)$ \\
$\quad$ (iv) Neuromuscular disease & 14 patients $(5.3 \%)$ \\
Prophylaxis with palivizumab &
\end{tabular}

* Median and range.

FH: family history; PICU: paediatric intensive care unit.

TABLE 2: Clinical and analytic characteristics of patients included in the BRUCIP study.

\begin{tabular}{ll}
\hline Variable & Value \\
\hline Origin of patients & $\begin{array}{l}\text { (i) Emergency dept.: } 30.2 \% \\
\text { (ii) Hospital ward: } 37 \% \\
\text { (iii) Other hospitals: } 31.7 \%\end{array}$ \\
\hline $\begin{array}{l}\text { Onset of respiratory distress until } \\
\text { admission to PICU* }\end{array}$ & 2 days (0-20 days) \\
\hline & (i) Severity (77.2\%) \\
Criteria for admission to PICU & $\begin{array}{l}\text { (ii) Blood gases }(1.9 \%) \\
\text { (iv) Presence of risk factors } \\
\text { (1.6\%) } \\
\text { (v) Mixed (6.1\%) }\end{array}$ \\
\hline pH on admission & 7.31 (6.97-7.54) \\
\hline pCO ${ }_{2}$ on admission (mmHg) & 53.35 (23-116) \\
\hline Positive RSV test & $78 \%$ \\
\hline${ }^{*}$ PICU: paediatric intensive care unit; RSV: respiratory syncytial virus.
\end{tabular}

stay in the PICU of patients who had a family or personal history of interest, compared to those who did not, is shown in Table 3.

Sixty-two patients $(23.7 \%)$ received no type of nebuliser treatment. The rest received inhaled therapy with adrenaline (38 patients, $14.5 \%$ ), hypertonic saline with adrenaline (24 patients, $9.2 \%$ ), salbutamol inhaled or nebulised (23 patients, $8.8 \%$ ), 3\% HSS (11 patients, $4.2 \%$ ), or several of these during the same stay (104 patients, 39.7\%). Almost one-quarter of patients $(24.8 \%, 65$ patients) received corticosteroids (mainly methylprednisolone) with a median duration of 4 days (0-13), 
TABLE 3: Stay in PICU according to presence of personal or family history.

\begin{tabular}{|c|c|c|c|}
\hline Factors analysed & Stay in PICU in patients with this factor (days) & Stay in PICU in patients without this factor (days) & $p$ \\
\hline Risk factors & $8(2-46)$ & $6(1-28)$ & 0.203 \\
\hline Prematurity & $8(2-46)$ & $6(1-28)$ & 0.213 \\
\hline Heart disease & $6.5(3-22)$ & $7(1-46)$ & 0.9 \\
\hline Atopic patient & $6.5(2-31)$ & $7(1-46)$ & 0.659 \\
\hline Atopic parents & $7(2-46)$ & $6(1-28)$ & 0.275 \\
\hline Smoking parents & $6(1-3)$ & $7(2-46)$ & 0.527 \\
\hline Patient with 1 sibling & $7(2-29)$ & $6(1-46)$ & 0.208 \\
\hline Patient with 2 or more siblings & $8(3-28)$ & $6(1-46)$ & 0.014 \\
\hline Vaccinated with palivizumab & $8(4-28)$ & $7(1-46)$ & 0.592 \\
\hline
\end{tabular}

Statistics test: Mann-WhitneyU test.

TABLE 4: Nebulised treatment of patients included in the BRUCIP study. PSS: physiological saline solution; HSS: hypertonic saline solution.

\begin{tabular}{lccc}
\hline Factors analysed & $N$ & Duration (days) & Length of PICU stay \\
\hline No nebulisation & $62(23.7 \%)$ & & $7.16 \pm 5.99$ \\
Salbutamol inhaled & $6(2.3 \%)$ & $3.58 \pm 3.11$ & $11.6 \pm 8.35$ \\
Salbutamol nebulised & $17(6.5 \%)$ & $4.25 \pm 6.66$ & $9.18 \pm 8.52$ \\
Adrenaline + PSS nebulised & $38(14.5 \%)$ & $2.06 \pm 2.43$ & $8.0 \pm 4.35$ \\
Adrenaline + 3\% HSS nebulised & $24(9.2 \%)$ & $4.43 \pm 4.27$ & $8.16 \pm 3.74$ \\
$3 \%$ HSS & $11(4.2 \%)$ & $4.16 \pm 3.54$ & $10.0 \pm 6.92$ \\
Several nebulisations & $104(39.7 \%)$ & & $7.78 \pm 4.18$ \\
\hline
\end{tabular}

TABLE 5: Antibiotic treatment of patients included in the BRUCIP study.

\begin{tabular}{|c|c|c|c|c|}
\hline Factors analysed & $N$ & Duration (days) & Antibiotic and $N$ & Indication \\
\hline Antibiotic therapy & 124 & 5 (IQR: 4-7) & $\begin{array}{c}\text { No antibiotic: } 101(39.1 \%) \\
\text { Cefotaxime: } 84(32 \%) \\
\text { Amoxicillin-clavulanic acid: } 30(11.6 \%) \\
\text { Macrolides: } 18(9.5 \%) \\
\text { Ampicillin: } 13(5 \%) \\
\text { Ceftriaxone: } 3(1.2 \%) \\
\text { Piperacillin-tazobactam: } 4(1.6 \%) \\
\text { Meropenem: } 2(0.8 \%) \\
\text { Vancomycin: } 5(2 \%) \\
\text { Others: } 9(3.5 \%)\end{array}$ & $\begin{array}{c}\text { Clinical: } 16(11 \%) \\
\text { Analytical: } 30(20.5 \%) \\
\text { Radiological: } 14(9.6 \%) \\
\text { Mix: } 69(47.3 \%) \\
\text { Others: } 17(11.6 \%)\end{array}$ \\
\hline
\end{tabular}

and 56.5\% (148 patients) received antibiotic therapy (Tables 4 and 5$)$. Three patients $(1.1 \%)$ received treatment with palivizumab during their PICU stay.

Three-quarters of patients $(76 \%, 199$ patients) received oxygen therapy for a median duration of 2 days (0-21 days) and 7 patients $(2.7 \%)$ received heliox. High-flow oxygen was used in $13.5 \%$ (35 patients), and some modality of NIV was used in $75.6 \%$ of patients (198 patients) (Figure 2). The modalities selected were as follows: CPAP (53 patients, $20.22 \%$ ), bilevel positive airway pressure (BiPAP) (11 patients, $4.2 \%$ ), and several modalities (134 patients, 51.7\%).

Sixty-four patients $(24.4 \%)$ required endotracheal intubation and connection to IMV for a median of 8 days (2-27). Of these, 34 (53.2\%) required endotracheal intubation before admission, 10 (15.6\%) on the day of admission, and 20
(31.2\%) after their first 24 hours of admission. Of the patients who required endotracheal intubation after PICU admission (32), $65.6 \%$ received some type of previous noninvasive respiratory support (high-flow oxygen was used in 6.3\% (2 patients), CPAP in $15.6 \%$ (5 patients), bilevel positive airway pressure (BiPAP) in $18.8 \%$ (6 patients), and several modalities in $25 \%$ ( 8 patients)). All intubated patients required sedoanalgesia perfusion for a median of 7 days (2-27); half of these ( 32 children) also received muscle relaxants for a median of 5 days (2-19). Six patients (2.3\%) were diagnosed with hospital-acquired pneumonia. The death rate was $0.4 \%$ (1 patient).

The length of stay in the PICU was longer in patients who required IMV (10 days, $4-46)$ than in those who did not (6 days, $1-21): p<0.0001$. Similarly, the stay was shorter in those 
TABLE 6: Data on multivariate analysis.

\begin{tabular}{lccc}
\hline Variable & $p$ & Confidence interval (95\%): lower limit & Confidence interval (95\%): upper limit \\
\hline Younger age & 0.013 & -0.416 & -0.049 \\
Antibiotic therapy & 0.006 & 0.456 & 2.763 \\
Invasive mechanical ventilation & 0.004 & 0.817 & 4.198 \\
Muscle relaxation & 0.000 & 3.271 & 7.786 \\
\hline
\end{tabular}

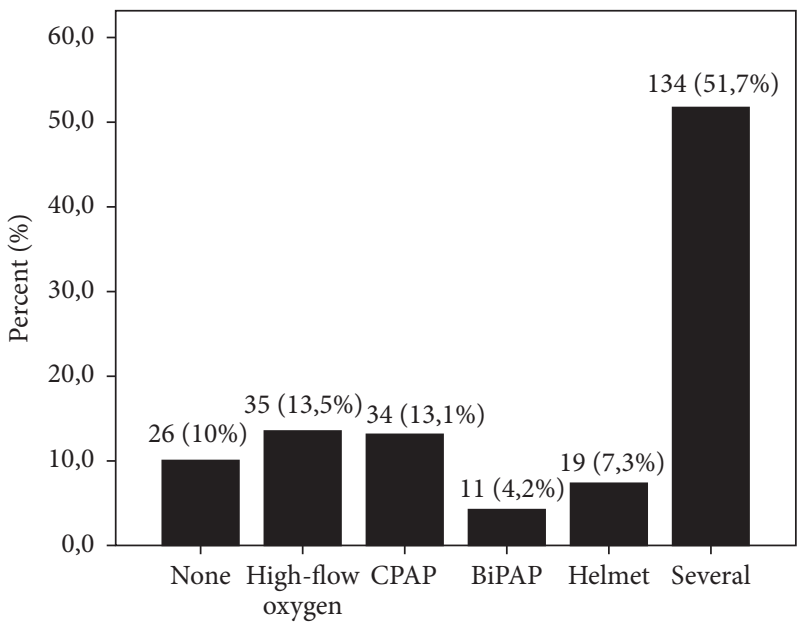

FIGURE 2: Noninvasive ventilation modalities.

who required NIV ( 6 days, $2-21$ ) than in those who did not (10 days, $4-46): p<0.0001$.

In the multivariate analysis, $32 \%$ of the longer stays were due to younger age, need to start antibiotics, IMV, and muscle relaxation, as these were risk factors that significantly increased length of stay in the PICU (Table 6).

\section{Discussion}

As far as we are aware, this is the first prospective multicentre study designed to describe the epidemiology of severe bronchiolitis cases admitted to PICUs in Spain. In our study, most of the patients admitted with severe $A B$ to the PICU were previously healthy patients with no risk factors and, therefore, were not candidates for receiving prophylaxis with palivizumab [16]. Of those with risk factors, the most common was prematurity, followed by heart disease; the percentage of patients with respiratory disease was lower than that published [17]. Although $26.7 \%$ of patients admitted to the PICU had risk factors for severe bronchiolitis, only 5.3\% met current criteria for palivizumab vaccination; this figure is higher than that found in other studies, which ranges from $1.9 \%$ to $3.7 \%$ [18-20]. Presenting some risk factor for severity was not associated with longer stays in the PICU, but there was a significant increase in the length of stay in patients with more siblings. In our study, exclusive breast-feeding did not reduce the stay, as reported by Vereen et al. [21]. The median age on admission to the PICU, percentage isolation of RSV, distribution of incidence of admissions by month, and mean duration of hospitalisation in the PICU were consistent with other epidemiological studies from other countries $[16,17]$.

This study highlights the wide variation of severe bronchiolitis management, as is described for mild and moderate bronchiolitis in general ward. We found a high frequency of use of some type of bronchodilator, despite current scientific evidence [1]. Furthermore, there was significant variation in the choice of nebulised treatment, from $23 \%$ of patients who did not receive any inhaled therapy to $40.8 \%$ of patients who received several types of inhaled medication during a single stay. Bronchodilators, salbutamol or adrenaline, have not been shown to improve outcomes, admission rate, or duration of hospitalisation in these patients [22, 23]. In our study, nebulised adrenaline was chosen as the main bronchodilator, likely based on articles that showed a slight short-term improvement in some clinical parameters [24].

Both physiological saline and 3\% HSS were used as diluents. The latest systematic review concluded that 3\% HSS can reduce the hospital stay in mild and moderate $\mathrm{AB}[25,26]$, although most of the literature published subsequently did not find any benefit in terms of length of stay [26-28]. These studies are not comparable with ours because nonsevere bronchiolitis cases were included.

In recent years, high-flow oxygen and NIV have become the respiratory support of choice in children with moderateto-severe bronchiolitis, so that most patients with severe $\mathrm{AB}$ in Spain are given some type of respiratory support on admission to the PICU, although neither the ideal modality and duration nor best method for weaning from these therapies has been defined. CPAP and high-flow oxygen can improve oxygenation and the $\mathrm{WOB}$ and reduce the need for intubation, although this is still questioned due to the contradictory findings of some studies $[10,29]$. Evidence to support the use of CPAP or high-flow oxygen is scant and is based on a few poorly designed clinical trials [30]. The latest systematic review did not find sufficient evidence for the use of high-flow oxygen in $\mathrm{AB}$ despite being very well tolerated, while its recommendation is based on a single study [31]; the same conclusion was reached for CPAP, similarly based on few clinical trials with a total of 50 patients and contradictory results [32]. In our study, patients with NIV (any modality) had a significantly shorter stay in the PICU.

Almost one-quarter of patients $(24.4 \%)$ in our study required intubation. These figures are similar to other studies $[16,17,33]$. Intubation is associated with the administration of sedoanalgesia ( $100 \%$ of ventilated patients) and even muscle relaxants (50\% of ventilated patients), increasing patients' 
length of stay. Likewise, as expected, we found that IMV is a risk factor for longer stay in the PICU and that the need for IMV may also actually be a marker of greater severity. Patients who received antibiotics also had a longer stay, probably because they were patients who developed a bacterial overinfection that delayed their clinical recovery.

Our mortality rate was lower than that reported in retrospective studies conducted in France with a mortality rate of 12.8/1000 [17] or in Switzerland with a rate of 11.6/1000 [18] and much lower than the rate of up to $42 / 1000$ reported in series in which populations with risk factors were specifically analysed [34-36]. This may be mainly due to variations in the severity of the different epidemics or the proportion of infants with risk factors for severity admitted to the PICU $[37,38]$.

This study has several limitations. First, not all patients admitted to PICUs during the epidemic season were included, given the care overload typical of the period, and, second, the voluntary participation in the study could imply some type of selection bias, although the sample is sufficiently large to be representative. The study design and objectives did not allow conclusive relationships to be established as regards the type of noninvasive respiratory support used (HFO, CPAP, and BiPAP) and need for IMV. Although the epidemiology was an objective of our study, most of the PICU participants only tested RSV as an etiological agent, and it is the only variable that we have presented in our study. The reason may be because the study was designed to assess habitual clinical practice and no recommendations or interventions were made. Finally, the hospital-acquired pneumonia rate may not be accurate, given the well-known problems in diagnosing ventilator-associated pneumonia, especially when the patient does not receive invasive ventilation [39].

This study also has some strengths. This is the first prospective Spanish multicentre study to describe the therapeutic management of severe BA. Moreover, it includes a large sample of cases, which means that the information collected accurately represents the current reality.

\section{Conclusions}

In summary, this study highlights the variation currently found in the management of severe AB in Spanish PICUs. We observed very frequent use of medications with no proven therapeutic effect (bronchodilators and, to a lesser extent, corticosteroids) and noninvasive respiratory support, with IMV in almost one-quarter of all children included. Younger age, antibiotic therapy, and need for endotracheal intubation (especially in patients receiving muscle relaxants) were associated with a longer stay in the PICU.

\section{Conflicts of Interest}

The authors declare that there are no conflicts of interest regarding the publication of this article.

\section{References}

[1] A. S. Lieberthal, H. Bauchner, C. B. Hall et al., "Diagnosis and management of bronchiolitis," Pediatrics, vol. 118, no. 4, pp. 1774-1793, 2006.
[2] H. C. Meissner, "Viral bronchiolitis in children," New England Journal of Medicine, vol. 374, no. 1, pp. 62-72, 2016.

[3] C. B. Hall, G. A. Weinberg, A. K. Blumkin et al., "Respiratory syncytial virus-associated hospitalizations among children less than 24 months of age," Pediatrics, vol. 132, no. 2, pp. e341-e348, 2013.

[4] S. A. Deshpande and V. Northern, "The clinical and health economic burden of respiratory syncytial virus disease among children under 2 years of age in a defined geographical area," Archives of Disease in Childhood, vol. 88, no. 12, pp. 1065-1069, 2003.

[5] C. B. Hall, G. A. Weinberg, M. K. Iwane et al., "The Burden of respiratory syncytial virus infection in young children," New England Journal of Medicine, vol. 360, no. 6, pp. 588-598, 2009.

[6] S. L. Ralston, A. S. Lieberthal, H. C. Meissner et al., "Ralston SL, Lieberthal AS, Meissner HC, et al. Clinical practice guideline: the diagnosis, management, and prevention of bronchiolitis. Pediatrics. 2014;134(5):e1474-e1502," Pediatrics, vol. 136, no. 4, p. 782, 2015.

[7] C. L. Carroll, E. V. S. Faustino, M. G. Pinto et al., "A regional cohort study of the treatment of critically ill children with bronchiolitis," Journal of Asthma, vol. 53, no. 10, pp. 1006-1011, 2016.

[8] H. C. Pierce, J. M. Mansbach, E. S. Fisher et al., "Variability of intensive care management for children with bronchiolitis," Hospital Pediatrics, vol. 5, no. 4, pp. 175-184, 2015.

[9] S. Essouri, M. Laurent, L. Chevret et al., "Improved clinical and economic outcomes in severe bronchiolitis with pre-emptive nCPAP ventilatory strategy," Intensive Care Medicine, vol. 40, no. 1, pp. 84-91, 2014.

[10] S. S. Ganu, A. Gautam, B. Wilkins, and J. Egan, "Increase in use of non-invasive ventilation for infants with severe bronchiolitis is associated with decline in intubation rates over a decade," Intensive Care Medicine, vol. 38, no. 7, pp. 1177-1183, 2012.

[11] S. Mayfield, J. Jauncey-Cooke, J. L. Hough, A. Schibler, K. Gibbons, and F. Bogossian, "High-flow nasal cannula therapy for respiratory support in children," The Cochrane Database of Systematic Reviews, vol. 3, Article ID CD009850, 2014.

[12] M. Donlan, P. S. Fontela, and P. S. Puligandla, "Use of continuous positive airway pressure (CPAP) in acute viral bronchiolitis: a systematic review," Pediatric Pulmonology, vol. 46, no. 8, pp. 736-746, 2011.

[13] Guía NICE 2015: National Collaborating Centre for Women's and Children's Health (UK) and National Institute for Health and Care Excellence (UK), Bronchiolitis. Diagnosis and Management of Bronchiolitis in Children, 2015, https://www.nice.org.uk/ guidance/ng9.

[14] C. D. González and P.-Y. E. González, "Acute bronchiolitis. Fundamentals of a rational protocol," Anales Espanoles de Pediatria, vol. 55, no. 4, pp. 355-364, 2001.

[15] M. Pons Odena, J. Caritg Bosch, and A. Palomeque Rico, "Bronquiolitis," in Manual de Cuidados Intensivos Pediátricos, J. Lopez Herce-Cid, C. Calvo Rey, C. Rey Galan, A. Rodriguez Nuñez, and A. Baltodano Aguero, Eds., pp. 114-120, 2013.

[16] D. Prais, T. Schonfeld, and J. Amir, "Admission to the intensive care unit for respiratory syncytial virus bronchiolitis: a national survey before palivizumab use," Pediatrics, vol. 112, no. 3, pp. 548-552, 2003.

[17] A.-L. Soilly, C. Ferdynus, O. Desplanches, M. Grimaldi, and J. B. Gouyon, "Paediatric intensive care admissions for respiratory syncytial virus bronchiolitis in France: results of a retrospective 
survey and evaluation of the validity of a medical information system programme," Epidemiology and Infection, vol. 140, no. 4, pp. 608-616, 2012.

[18] T. M. Berger, C. Aebi, A. Duppenthaler, and M. Stocker, "Prospective population-based study of rsv-related intermediate care and intensive care unit admissions in Switzerland over a 4-year period (2001-2005)," Infection, vol. 37, no. 2, pp. 109-116, 2009.

[19] G. Cilla, A. Sarasua, M. Montes et al., "Risk factors for hospitalization due to respiratory syncytial virus infection among infants in the Basque Country, Spain," Epidemiology and Infection, vol. 134, no. 3, pp. 506-513, 2006.

[20] L. Chevret, B. Mbieleu, S. Essouri, P. Durand, S. Chevret, and D. Devictor, "Bronchiolitis treated with mechanical ventilation: prognosis factors and outcome in a series of 135 children," Archives de Pediatrie, vol. 12, no. 4, pp. 385-390, 2005.

[21] S. Vereen, T. Gebretsadik, T. V. Hartert et al., "Association between breast-feeding and severity of acute viral respiratory tract infection," Pediatric Infectious Disease Journal, vol. 33, no. 9, pp. 986-988, 2014.

[22] A. M. Gadomski and M. B. Scribani, "Bronchodilators for bronchiolitis," The Cochrane Database of Systematic Reviews, vol. 6, Article ID CD001266, 2014.

[23] L. Hartling, L. M. Bialy, B. Vandermeer et al., "Epinephrine for bronchiolitis," Cochrane Database of Systematic Reviews, no. 6, Article ID CD003123, 2011.

[24] P. Walsh, J. Caldwell, K. K. McQuillan, S. Friese, D. Robbins, and S. J. Rothenberg, "Comparison of nebulized epinephrine to albuterol in bronchiolitis," Academic Emergency Medicine, vol. 15, no. 4, pp. 305-313, 2008.

[25] L. Zhang, R. A. Mendoza-Sassi, C. Wainwright, and T. P. Klassen, "Nebulised hypertonic saline solution for acute bronchiolitis in infants," The Cochrane Database of Systematic Reviews, no. 7, Article ID CD006458, 2013.

[26] C. Maguire, H. Cantrill, D. Hind, M. Bradburn, and M. L. Everard, "Hypertonic saline (HS) for acute bronchiolitis: systematic review and meta-analysis," BMC Pulmonary Medicine, vol. 15, no. 1, article 148, 2015.

[27] T. A. Florin, "Randomised controlled trial: nebulised hypertonic saline does not reduce hospital length of stay in acute bronchiolitis," Evidence-Based Medicine, vol. 20, no. 3, article 106, 2015.

[28] M. L. Everard, D. Hind, K. Ugonna et al., "SABRE: a multicentre randomised control trial of nebulised hypertonic saline in infants hospitalised with acute bronchiolitis," Thorax, vol. 69, no. 12, pp. 1105-1112, 2014.

[29] I. P. Sinha, A. K. S. McBride, R. Smith, and R. M. Fernandes, "CPAP and high-flow nasal cannula oxygen in bronchiolitis," Chest, vol. 148, no. 3, pp. 810-823, 2015.

[30] L. P. Thia, S. A. McKenzie, T. P. Blyth, C. C. Minasian, W. J. Kozlowska, and S. B. Carr, "Randomised controlled trial of nasal continuous positive airways pressure (CPAP) in bronchiolitis," Archives of Disease in Childhood, vol. 93, no. 1, pp. 45-47, 2008.

[31] S. Beggs, Z. H. Wong, S. Kaul, K. J. Ogden, and J. A. E. Walters, "High-flow nasal cannula therapy for infants with bronchiolitis," The Cochrane Database of Systematic Reviews, vol. 1, Article ID CD009609, 2014.

[32] K. R. Jat and J. L. Mathew, "Continuous positive airway pressure (CPAP) for acute bronchiolitis in children," The Cochrane Database of Systematic Reviews, vol. 1, Article ID CD010473, 2015.
[33] J. M. Mansbach, P. A. Piedra, M. D. Stevenson et al., "Prospective multicenter study of children with bronchiolitis requiring mechanical ventilation," Pediatrics, vol. 130, no. 3, pp. e492e500, 2012.

[34] T. F. Feltes, A. K. Cabalka, H. C. Meissner et al., "Palivizumab prophylaxis reduces hospitalization due to respiratory syncytial virus in young children with hemodynamically significant congenital heart disease," Journal of Pediatrics, vol. 143, no. 4, pp. 532-540, 2003.

[35] K. Thorburn, "Pre-existing disease is associated with a significantly higher risk of death in severe respiratory syncytial virus infection," Archives of Disease in Childhood, vol. 94, no. 2, pp. 99-103, 2009.

[36] F. W. Moler, A. S. Khan, J. N. Meliones, J. R. Custer, J. Palmisano, and T. C. Shope, "Respiratory syncytial virus morbidity and mortality estimates in congenital heart disease patients: a recent experience," Critical Care Medicine, vol. 20, no. 10, pp. 1406$1413,1992$.

[37] M. Grimaldi, B. Cornet, C. Milou, and J. B. Gouyon, "Prospective regional study of an epidemic of respiratory syncytial virus (RSV) bronchiolitis," Archives de Pédiatrie, vol. 9, no. 6, pp. 572580, 2002.

[38] M. Eriksson, R. Bennet, M. Rotzén-Ostlund, M. von Sydow, and B. Z. Wirgart, "Population-based rates of severe respiratory syncytial virus infection in children with and without risk factors, and outcome in a tertiary care setting," Acta Paediatrica, vol. 91, no. 5, pp. 593-598, 2002.

[39] A. C. Kalil, M. L. Metersky, M. Klompas et al., "Management of adults with hospital-acquired and ventilator-associated pneumonia: 2016 clinical practice guidelines by the Infectious Diseases Society of America and the American Thoracic Society," Clinical Infectious Diseases, vol. 63, no. 5, pp. 575-582, 2016. 


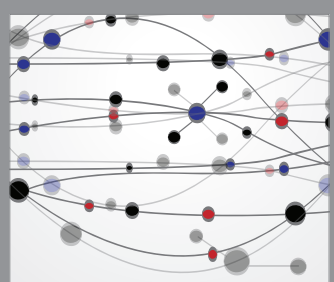

The Scientific World Journal
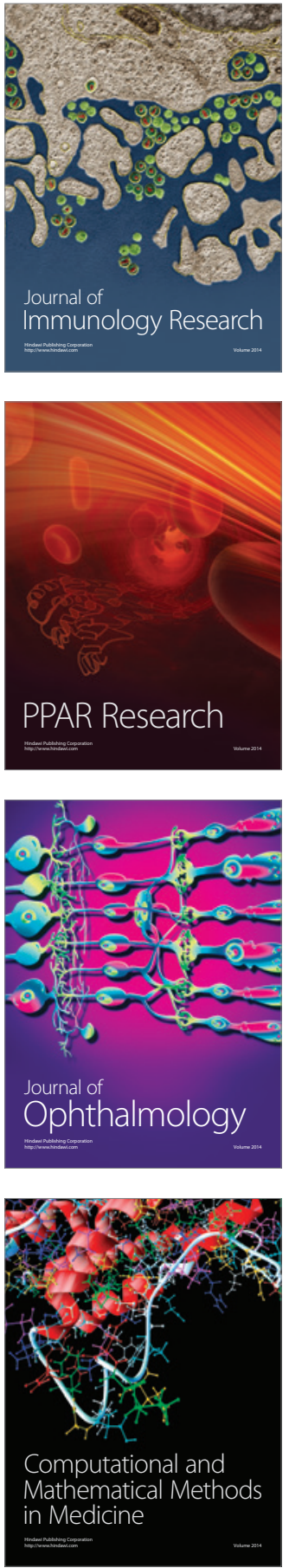

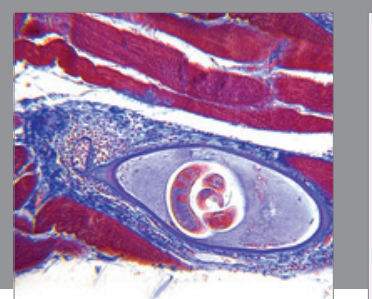

Gastroenterology Research and Practice
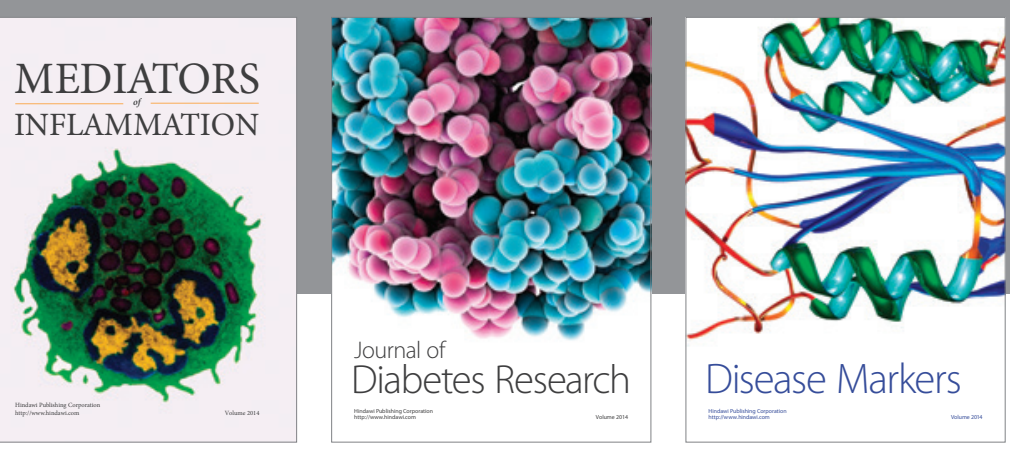

Disease Markers

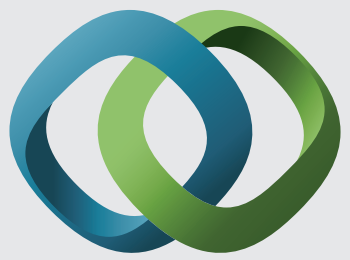

\section{Hindawi}

Submit your manuscripts at

https://www.hindawi.com
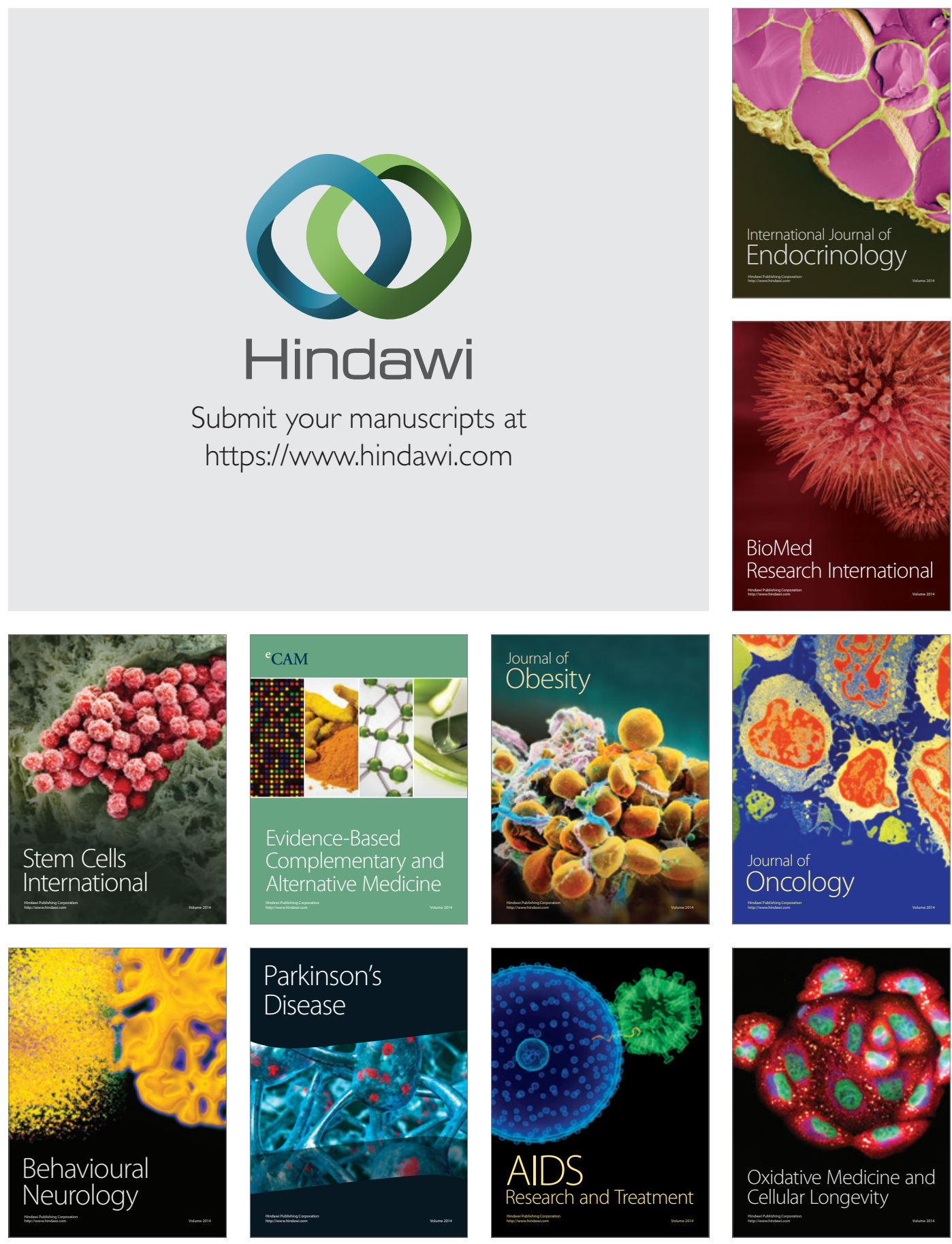